\title{
Adição de uma associação polimérica a um solo argilo-arenoso com vistas à estabilização química de materiais para pavimentos
}

\author{
Addition of a polymeric association to a \\ clayey-sandy-silty soil aiming to reach \\ the chemical stabilization for use as \\ pavement materials
}

Lucas Ferreira Melo Machado ${ }^{1}$, Erinaldo Hilário Cavalcante ${ }^{1}$,
Fernando Silva Albuquerque ${ }^{1}$, Angela Teresa Costa Sales ${ }^{1}$,

\author{
${ }^{1}$ Laboratório de Geotecnia e Pavimentação - GEOPAV - DEC/UFS CEP: 491000 - 000, Aracaju, SE \\ e-mail: lucas.civil@yahoo.com.br; erinaldohc@gmail.com; albuquerque.f.s@uol.com.br; angelasales19@gmail.com
}

\begin{abstract}
RESUMO
Visando à redução dos custos das obras de pavimentação rodoviária, sempre se procura utilizar materiais locais, preferencialmente os solos de jazidas mais próximas da construção. Às vezes, existem várias jazidas de solos inadequados para o uso, mas que podem ter suas propriedades melhoradas, aplicando-se a técnica correta de melhoramento, como a estabilização química, na qual se enquadra o uso de polímeros ou associações poliméricas. Com este trabalho propõe-se avaliar o uso de uma associação polimérica, na melhoria do comportamento geotécnico de um solo com problemas de resistência, visando ao seu uso como material de pavimentos rodoviários de baixo volume de tráfego. Esta pesquisa está baseada nos ensaios de caracterização geotécnica, compactação, ISC, (UCS RCS e permeabilidade, executados com o solo puro e com adição de material polimérico em proporções variando entre $2 \%$ e $6 \%$. A pesquisa revelou aumentos consideráveis nos valores de ISC e RCS. Os resultados obtidos revelaram que o uso da associação polimérica resultou em diminuição da plasticidade, aumento no teor de umidade ótimo, redução do peso específico aparente seco e da expansão do solo. Concluiu-se, dessa forma, que, à luz das especificações vigentes, a adição de 6\% da associação polimérica ao solo classificado como argilo-areno-siltoso de expressiva plasticidade promoveu significativas melhorias nas propriedades geotécnicas do solo.
\end{abstract}

Palavras-chave: Estabilização de solos; Polímero industrial; Materiais para pavimentos.

\begin{abstract}
In order to reduce road-paving costs, the aim is always to use local materials, namely earth from deposits closer to the construction. Occasionally several unsuitable soil deposits are available, but whose properties can be improved, adopting the correct upgrade technique, such as chemical stabilization involving the use of polymers or polymeric association. The purpose of this study is to assess the use of a polymeric association to improve the geotechnical behavior of a soil with strength problems, in order to deploy it as material for paving roads with light traffic. This study is based on geotechnical characterization, compaction, CBR, unconfined compressive strength - UCS - and permeability tests performed on pure soil and on this soil with a polymer added in proportions varying from $2 \%$ to $6 \%$. A substantial increase was noted in CBR and UCS figures. The results revealed that using the polymeric association reduced plasticity, increased optimum moisture content, reduced dry apparent specific weight and expanded the soil. The conclusion, therefore, was that, in light of the prevailing specifications, the addition of $6 \%$ polymeric association to the clayey-sandysilty soil with considerable plasticity brought significant improvements to the soil's geotechnical properties.
\end{abstract}

Keywords: Soil stabilization; Industrial polymer; Materials for pavement.

\section{INTRODUÇÃO}

Na área da construção de infraestruturas, a pavimentação rodoviária é uma obra que tem o objetivo inicial de melhorar as condições de trafegabilidade, no sentido operacional, quando se obtém uma superfície mais regu- 
lar, aderente, durável e que produza menos ruídos no contato direto com os pneus, oferecendo ao tráfego conforto e segurança. Nesse tipo de construção, sempre se procura utilizar materiais locais, visando-se à redução dos custos de execução, operação e de manutenção ao longo da vida útil do pavimento [6].

Para isso, são necessárias análises que demonstrem a disponibilidade de solos na região, levando-se em consideração, do ponto de vista econômico, a sua distância à obra, e do ponto de vista técnico, o seu comportamento geotécnico à luz das especificações rodoviárias vigentes [29].

Há exemplos de vários outros autores, como por exemplo, CORDEIRO [9] que destaca a construção rodoviária tradicionalmente mobiliza grandes quantidades de solo, um recurso natural não renovável, que cada vez mais se torna escasso com as características que se deseja para a aplicação nesse tipo de obra de infraestrutura.

Além da carência de material natural adequado, há também limitações impostas pelos órgãos de regulação ambiental, que contribuem para diminuir consideravelmente as opções, como a extração de solos adequados em novas jazidas [26]. Por outro lado, há a disponibilidade de solos que não se enquadram nas especificações tradicionais de materiais para pavimentação rodoviária, mas que podem ter suas características melhoradas (por exemplo, resistência, permeabilidade e deformabilidade) para o uso, especialmente em pavimento de menor volume tráfego e custo, empregando-se, para isso, um dos processos de estabilização de solos disponíveis [8].

Entre os tipos de estabilização mais empregados, pode-se citar o método químico, em que são utilizados aditivos com a função de interagir com o solo, melhorando suas propriedades e tornando-as mais estáveis. Os principais tipos de aditivos usados com essa finalidade são a cal, o cimento Portland, asfalto e emulsões ou demais produtos químicos industrializados, a exemplo do polímero acrílico industrial [7].

A propósito, o polímero industrial tem sido utilizado no Nordeste, especificamente no Estado de Pernambuco, por uma empresa local, de maneira empírica, e a prática tem revelado sucesso nos vários casos de obra, especialmente no que se refere à impermeabilização do solo, mantendo-o estável contra as intempéries [23].

Dentro desse contexto, esta pesquisa visa avaliar o uso de uma associação polimérica, tendo como matriz um polímero acrílico industrial como agente estabilizante aplicado a um solo de matriz argilo-arenosa, partindo-se da hipótese de que o aditivo promoverá melhorias em suas propriedades geotécnicas, à luz de ensaios tradicionais, e assim, poder indicar o uso dessa mistura como material na construção de camadas de sub-base e/ou base de pavimentos rodoviários.

\section{REVISÃO BIBLIOGRÁFICA}

\subsection{Estabilização de solos para fins de pavimentação}

Em obras de pavimentação, o solo se faz presente desde o subleito, na sub-base, e pode fazer parte, ainda, em diversas situações, do revestimento primário e da base [29]. Estabilizá-lo para este fim significa utilizar-se de técnicas para fazer com que o solo adquira a capacidade de suportar esforços e carregamentos induzidos pelo tráfego aplicado sobre o pavimento, e fazer, também, com que se torne resistente aos desgastes que ocorrem naturalmente nas condições mais adversas, o que se traduz em durabilidade.

Dessa forma, estabilização de solos refere-se a todas as técnicas, naturais ou não, que se apliquem aos solos, visando melhorar as suas características mecânicas para que perdurem durante toda a vida útil [27].

As principais características melhoradas quando um solo é estabilizado podem ser: redução da plasticidade do solo; aumento de resistência ou de capacidade de suporte diante das solicitações; aumento da durabilidade e redução da expansão. Entre os processos de estabilização disponíveis, os mais utilizados são as estabilizações mecânica, granulométrica (ou física) e a química [21].

A estabilização mecânica, sem dúvida, é a mais comum, pois, por consistir na compactação do solo, sempre é necessária em qualquer obra de terra, visando-se ao aumento da densidade e à diminuição do índice de vazios, o que resulta, em geral, no aumento da resistência e na capacidade de suporte do solo, conforme mencionado por SOUSA [28].

Ainda de acordo com o citado autor, a estabilização granulométrica faz com que se obtenha um solo híbrido, a partir de uma mistura de solos, com uma distribuição granulométrica bem graduada. Vale ressaltar, para complementar a definição, que esse processo é aplicado à mistura de solos granulares com argilosos ou siltosos, visando conferir parcela de resistência coesiva ao solo granular e, por outro lado, resistência por atrito ao solo argiloso ou siltoso. Trata-se de uma técnica também empregada para estabilizar agregados pétreos, tornando-os mais densos. 
Por fim, conforme mencionado por OLIVEIRA [24], a estabilização química é o procedimento baseado nas reações químicas que ocorrem entre os materiais, a exemplo dos aditivos adicionados aos solos, visando modificar as propriedades da matriz, no caso, o solo. Para isso, são usados produtos denominados aditivos químicos, a exemplo dos cimentos (asfálticos e Portland), cal e polímeros industriais especiais.

\subsection{Aspectos gerais da mistura solo-polímero}

Entre os aditivos estabilizantes que podem ser utilizados em solos, o polímero acrílico detém potencial de uso relevante. Devido à natureza comercial dos fabricantes desse tipo de aditivo, não há a divulgação detalhada de suas composições químicas exatas. Em termos de aplicação, normalmente são empregados, para fins de estabilização de solos, os copolímeros acrílicos ou acetatos de vinila. Esses aditivos atuam envolvendo as partículas de solo, impermeabilizando os grãos após a evaporação da água, formando ligações "físicas" entre elas [30].

De acordo com SOLIZ [29], a estabilização promovida com o uso de polímeros está baseada, na maioria das vezes, na eficiência do aditivo em repelir a água, bem como dotar o solo da parcela coesiva, a partir de polimerização, que pode ser entendida como uma forma de cimentação. Isto corrobora opinião de INGLES \& METCALF [21], os quais afirmam que os polímeros tendem a flocular a estrutura dos solos, aumentando a sua resistência ao cisalhamento.

Casos de obra relatados acerca do emprego de polímeros em obras de trechos de estradas de Pernambuco tem revelado a eficácia do produto na prevenção contra a erosão, bem como aumento do ISC, conforme mencionado por MARTINS [22] e MORAIS [23].

Outros casos de aplicação de polímeros em obras de terra podem ser encontrados junto aos principais fabricantes deste tipo de produto, a exemplo da execução de um pavimento de baixo volume de tráfego, situado em estrada da zona rural, numa área pertencente à Universidade da Pensilvânia, nos Estados Unidos, assim como o caso da estrada construída numa base militar da Rússia, para o tráfego de tanques militares [11].

\subsection{Breve histórico de pesquisas com a mistura solo - polímero para pavimentação}

Com a finalidade de abordar cientificamente essa técnica de estabilização para fins geotécnicos, têm sido iniciados estudos baseados em ensaios de laboratório acerca do uso de polímeros ou associação de polímeros adicionados a solos para camadas de pavimentos rodoviários.

Entre os autores que têm abordado esse tema nos últimos anos, TINGLE et al. [30] mencionam o emprego de aditivos denominados por eles como não tradicionais. Esses autores analisaram os efeitos de sete diferentes tipos de estabilizantes, entre eles os polímeros acrílicos, em misturas com diferentes tipos de solos encontrados nos Estados Unidos. Os referidos autores classificaram as melhorias alcançadas em termos de resistência, estabilidade volumétrica (neutralização de expansão ou contração) e impermeabilização, promovidas pelos agentes estabilizadores. Os autores destacaram ainda que os polímeros são mais eficazes quando adicionados a solos granulares, não sendo, na opinião deles, adequados para uso com solos finos, pelo fato das partículas desses solos possuírem área específica superficial maior.

No Brasil, as pesquisas envolvendo a temática de estabilização de solos com polímero ainda são muito incipientes e recentes. MORAIS [23] utilizou teores de associação polimérica nas proporções de $1 \%$, $3 \%$ e $5 \%$, em massa, a um solo argiloso de baixa compressibilidade (CL), ou tipo A-6, comumente encontrado no Estado de Sergipe. Os resultados obtidos indicaram aumentos consideráveis nos valores do ISC do solo.

PATRÍCIO [25] utilizou percentuais de 2,2\%, 6,4\% e 10,7\% da mesma associação polimérica utilizada na presente pesquisa, em mistura com quatro solos arenosos provenientes da área da grande Recife. Os resultados obtidos pelo mencionado autor revelaram aumento nos valores de Índice Suporte Califórnia e redução nos valores de expansão, mas também foram obtidas expressivas melhorias nas resistências à compressão simples e à tração por compressão diametral, em que os melhores ganhos de resistência foram do solo classificado como areia-siltosa fina, tipo A-2-4. Em termos de permeabilidade, os resultados obtidos não foram satisfatórios, tendo-se em vista que o coeficiente de permeabilidade dos solos aumentou mesmo após a estabilização, quando se esperava que diminuísse.

A literatura revela que o processo de estabilização química de solos usando-se cal e cimento não é mais considerado novidade no ramo da pavimentação, mas o uso de polímeros biodegradáveis para este fim ainda é muito raro, especialmente no Brasil. Além dos benefícios físicos e mecânicos que esse processo pode trazer, há também a redução de custo na execução das obras, com o aproveitamento de materiais locais estabilizados. 
Diante disso, crescem a necessidade e a importância de investigar o processo, utilizando novos agentes aditivos, com base em ensaios de laboratório, pesquisando-se as evidências científicas dos benefícios que podem ser adquiridos com o uso desses tipos de materiais que possuem propriedades aglutinantes e impermeabilizantes muito atraentes, os polímeros.

\section{MATERIAIS E MÉTODOS}

\subsection{Materiais utilizados}

Foi utilizado solo de textura argilo-areno-siltosa, numa jazida denominada Cajueiro, situada no município de São Cristóvão, Estado de Sergipe. Na Figura 1 podem-se observar aspectos da textura característica do solo utilizado na pesquisa, constituído de frações representativas de argila, silte e areia.

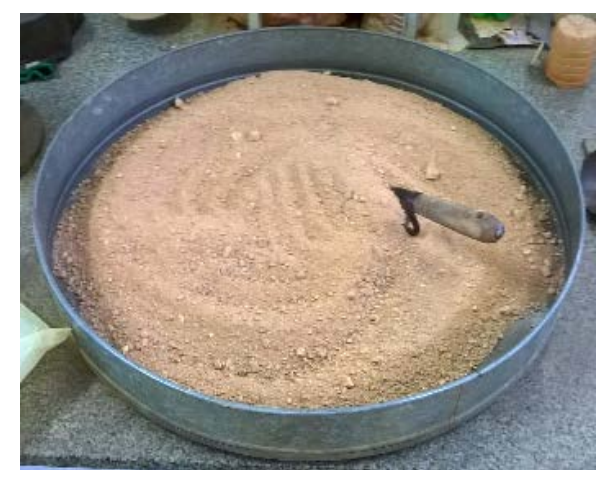

Figura 1: Aspetos da textura da mostra de solo puro seca ao ar.

Agentes estabilizantes: como agente de estabilização química, foi utilizado um polímero industrial, material desenvolvido à base de Éster do Ácido Acrílico, produto biodegradável, não contaminante e solúvel na presença de água, classificado de acordo com a norma ambiental NBR 10004:2014 [5] como resíduo classe II A (não inerte), a partir dos ensaios de solubilização e lixiviação apresentados pela cedente, em que apenas os parâmetros Ferro e Surfactantes ultrapassaram os limites do Anexo G da referida norma, mas que não representam qualquer risco ao meio ambiente. A Tabela 1 mostra a composição química do aditivo empregado, onde se pode observar que o produto é composto de mais de $50 \%$ de polímero acrílico, seguido de até 47\% de água, e o restante constituído de amônia e aditivos não perigosos. Trata-se de uma emulsão aquosa polimérica acrílica, de cor branca.

Tabela 1: Composição química e propriedades físicas do aditivo usado nesta pesquisa.

\begin{tabular}{|c|c|c|c|}
\hline \multicolumn{2}{|l|}{ Composição química } & \multicolumn{2}{|c|}{ Propriedades físicas } \\
\hline Substância & (\%), em massa & Estado físico & Líquido \\
\hline Polímero acrílico & $>50$ & Odor & Imperceptível \\
\hline Água & $<47$ & Ponto de ebulição & $100^{\circ} \mathrm{C}$ \\
\hline Amônia & $<1$ & Massa específica & 1,15 a $1,17\left(\mathrm{~g} / \mathrm{cm}^{3}\right)$, a $23^{\circ} \mathrm{C}$ \\
\hline Aditivos não perigosos & $<3$ & $\mathrm{PH}$ & 7 a 8 \\
\hline
\end{tabular}

O produto já é bastante empregado em algumas obras na área metropolitana de Recife, pela empresa ViaEncosta, que cedeu o produto. Associado ao polímero, também foram usados nesta pesquisa um redutor de plasticidade, denominado TerraDry® e um acelerador de pega, o Polycure $\complement$.

Conforme sugerido pela empresa cedente do produto (Viaencosta Engenharia Ambiental), quando a matriz do solo possuir fração argilosa deve ser adicionado ao polímero acrílico, um redutor de plasticidade, que consiste num composto químico de silício e hidrogênio, na forma líquida, num porcentual correspondente a $10 \%$ do teor de polímero. Além disso, deve-se também utilizar acelerador de pega, produto fornecido em pó, solúvel em água, não contaminante, que acelera a cura da mistura solo-polímero acrílico. Neste caso, o fabricante recomenda o emprego de um percentual correspondente a 50\%, em massa, do teor de polímero usado na mistura com o solo. A Figura 2 mostra os recipientes contendo os materiais que formam o composto 
químico usado no processo de estabilização de solo com o polímero utilizado nesta pesquisa.

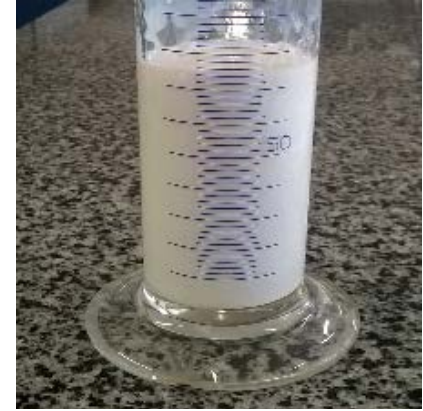

(a)

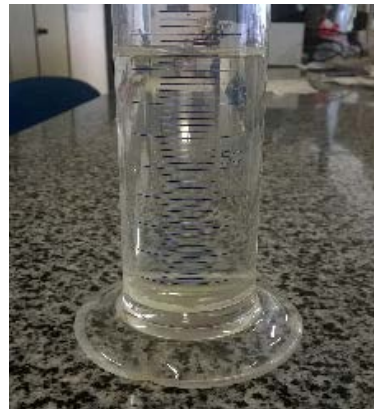

(b)

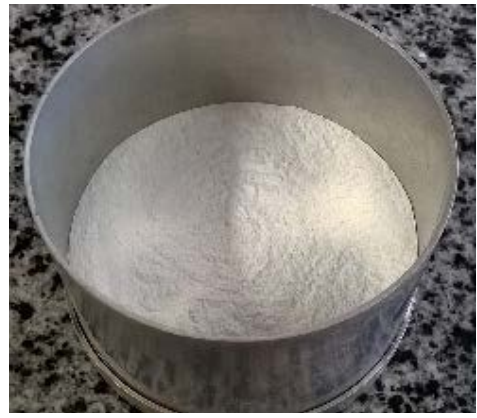

(c)

Figura 2: Materiais do composto polimérico: (a) Polímero industrial (b) Redutor de plasticidade (c) Acelerador de pega.

\subsection{Métodos experimentais adotados na preparação da mistura solo-polímero}

Para esta pesquisa, foram realizadas adições de polímero acrílico nas porcentagens de $2 \%$, $4 \%$ e $6 \%$ em relação à massa de solo seca. A ordem estabelecida para a mistura com o solo cumpriu o seguinte roteiro: i) adicionou-se ao solo o acelerador de cura e procedeu-se a homogeneização da mistura; ii) em seguida, num recipiente separado, misturou-se o redutor de plasticidade com o polímero acrílico, agitando-se a mistura com o auxílio de uma haste metálica; iii) finalmente, o composto líquido preparado em "ii" foi adicionado ao solo anteriormente misturado ao acelerador de cura, realizando-se a homogeneização da mistura solo-associação polimérica.

Com as amostras de solo puro foi realizada a caracterização geotécnica: ensaios de análise granulométrica por peneiramento e sedimentação, seguindo os procedimentos da norma DNER ME 051 [12]; ensaio de massa específica real, DNER ME 093 [14] e os ensaios de Limites de Atterberg para determinação dos limites de plasticidade (LL) e de liquidez (LP), conforme as normas DNER ME 082 [13] e DNER ME 122 [15] respectivamente.

Prosseguindo-se, com as amostras de solo puro e solo-polímero foram realizados os ensaios de compactação, de acordo com a norma NBR 7182 [1], para se obter os valores de teor de umidade ótima e peso específico aparente seco máximo do solo puro e das misturas solo-polímero. Esses ensaios foram realizados com o emprego da energia intermediária, uma vez que as normas DNER ES 301 [17] e DNER ES 303 [18] facultam a escolha da energia para bases e sub-bases de pavimentos, ficando a critério das especificações do projeto.

Com os resultados obtidos nos ensaios de compactação, foram moldados corpos de prova, nas condições consideradas ótimas, as quais foram submetidas aos ensaios de Índice Suporte Califórnia, realizados de acordo com a norma NBR 9895 [2], para a obtenção dos valores de ISC e expansão do solo puro e das misturas. Cabe mencionar que para se realizar esse tipo de ensaio, tanto após a moldagem quanto após a cura de sete dias em câmara úmida, as amostras ficaram imersas em água durante quatro dias, visando-se avaliar suas propriedades expansivas.

Como o polímero se trata de um agente aglutinante, para o qual não se tem um histórico de pesquisas revelando quais os melhores tempos de cura, se procurou adotar os tempos de cura que são utilizados para outros tipos de materiais, a exemplo do concreto e o solo-cimento, que possuem uma vasta literatura disponível.

Da mesma forma, com base ainda nos dados de compactação, foram preparadas amostras para os ensaios de resistência à compressão simples (RCS), seguindo a norma NBR 12770 [3], moldando-se corpos de prova compactados em cinco camadas sucessivas, com a aplicação de 20 golpes em cada camada com soquete grande, ficando a amostra com dimensões de $200 \mathrm{~mm}$ de altura por $100 \mathrm{~mm}$ de diâmetro. Neste caso, os corpos de prova produzidos a partir das amostras do solo com adição do polímero ficaram em câmara úmida para efeitos de cura sob temperatura e umidade controladas, durante os períodos de sete e vinte e oito, respectivamente. Após esses períodos, os corpos de prova foram submetidas à ruptura sob deformação controlada, da ordem de $1 \mathrm{~mm} / \mathrm{min}$, numa máquina universal de ensaios, marca EMIC, modelo DL 20000, com célula de carga com capacidade de $200 \mathrm{kN}$.

Foram realizados ensaios de resistência à tração por compressão diametral (RT), seguindo-se o procedimento adaptado da norma ME 181 [16], com corpos de prova e energia de compactação idênticos ao ensaio 
de RCS. Neste caso, os corpos de prova da mistura solo-polímero também foram submetidos ao processo de cura de sete e vinte e oito dias, e, logo após, foram ensaiados na mesma máquina usada para o ensaio de RCS.

Para determinação do coeficiente de permeabilidade do solo e das misturas, foram realizados ensaios de permeabilidade de carga variável, de acordo com a norma NBR 14545 [4]. A preparação dos corpos de prova das misturas se deu com a cura por sete dias em câmara úmida. Em seguida, os corpos de prova foram submetidos à saturação, durante um período de 24 horas, de forma que todos os vazios das amostras ficassem completamente preenchidos com água, para enfim, se proceder aos ensaios de permeabilidade. Para todos os ensaios foram tomados os cuidados para que as umidades de moldagem não divergissem mais que $0,5 \%$ do teor de umidade ótima, e que o grau de compactação permanecesse entre 99\% e 101\%.

\section{RESULTADOS}

\subsection{Ensaios de caracterização geotécnica e compactação}

Com base nos resultados dos ensaios de análise granulométrica (por peneiramento e sedimentação) realizados com o solo puro, foram obtidas as seguintes frações granulométricas do solo: 5,86\% de pedregulho; 30,21\% de areia; 30,76\% de silte e 33,17\% de argila, de acordo com escala granulométrica do DNIT. Estes percentuais revelam que o solo escolhido para a pesquisa possui frações de finos predominantes, somando 63,93 \% de material que passa na peneira de número 200 (abertura de 0,074 mm). A Figura 3 apresenta a curva de distribuição granulométrica, onde se pode constatar que cerca de $85 \%$ das partículas tem diâmetro igual ou menor que $0,4 \mathrm{~mm}$. Portanto, trata-se de solos finos, inadequados para uso na pavimentação [29].

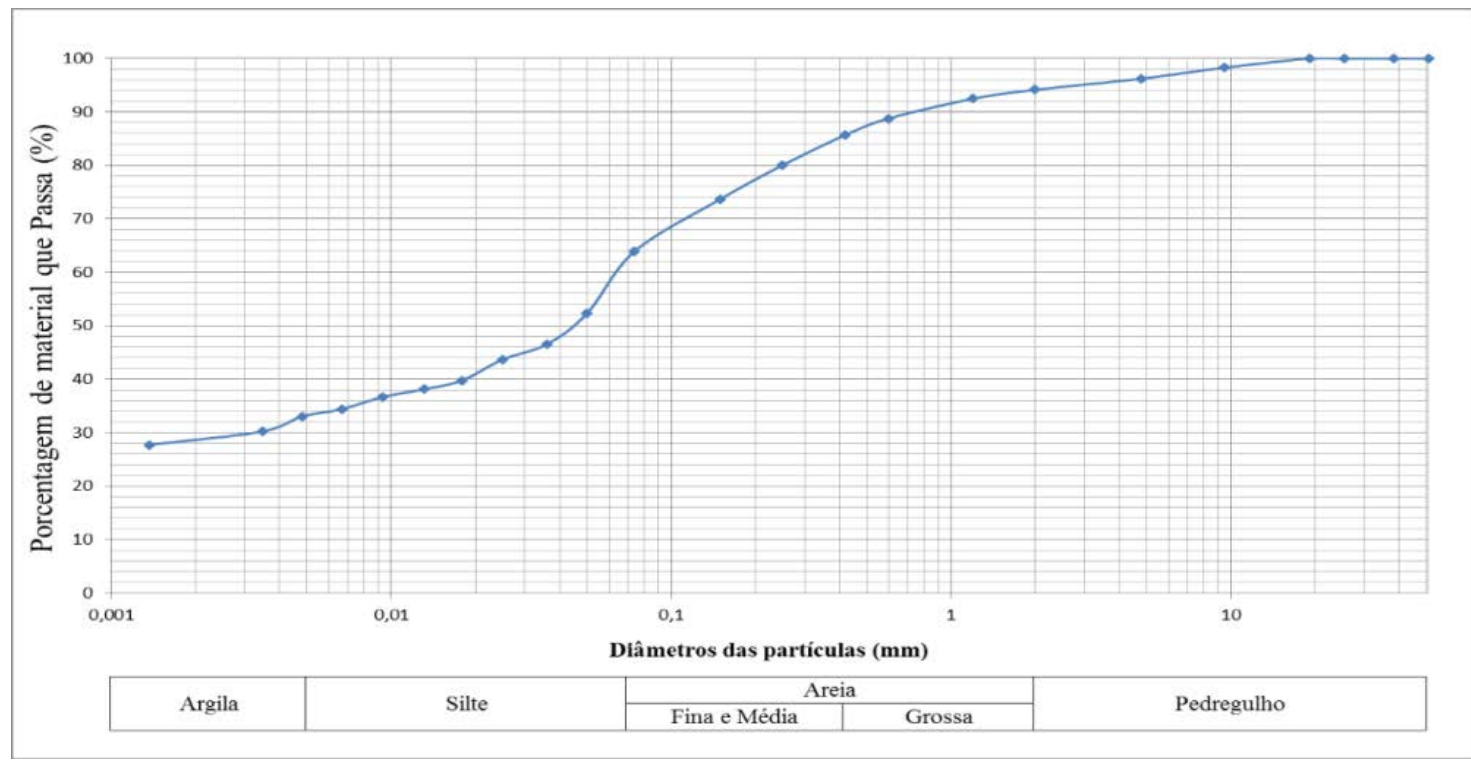

Figura 3: Curva de distribuição do tamanho das partículas enquadrada na escala granulométrica do DNIT.

Os valores obtidos para a massa específica real, os limites de Atterberg e o enquadramento do solo e das misturas de solo e polímero (nas proporções de 2\%, 4\% e 6\%) nos sistemas de classificação TRB AASHTO (Transportation Research Boarding - American Association of State Highway and Transportation Officials) e SUCS - Sistema Unificado de Classificação de Solos estão mostrados na Tabela 2.

Os resultados mostrados na Tabela 2 mostram que o valor da massa específica real do solo sofreu uma discreta redução com a adição da associação polimérica, variando de 2,644 g/ $/ \mathrm{cm}^{3}$ para 2,636 g/ $/ \mathrm{cm}^{3}$, valor alcançado já com o percentual de $4 \%$. Essa diminuição já era esperada, uma vez que a massa específica do polímero é menor do que a do solo. Observou-se, também, a diminuição nos valores do limite de liquidez e do índice de plasticidade do solo, que caiu de $20 \%$ para $13,5 \%$, significando que o solo tornou-se menos plástico, favorecendo a aplicação desejada. De acordo com o sistema TRB-AASHTO pode-se enquadrar o solo e as misturas na classe $\mathrm{A}-6$, visto que $64 \%$ de material passou na peneira $\mathrm{n}^{\circ}$. $200(0,074 \mathrm{~mm})$, possuindo $\mathrm{LL}$ menor que 40 e IP superior a 10, classificando o solo e as misturas como argila siltosa de média plasticidade. 
Tabela 2: Caracterização e classificação geotécnica do solo e das misturas usadas nesta pesquisa.

\begin{tabular}{|c|c|c|c|c|c|}
\hline \multicolumn{2}{|c|}{ CARACTERÍSTICAS } & SOLO PURO & $\begin{array}{l}\text { SOLO + 2\% DE } \\
\text { ASSOCIAÇÃO } \\
\text { POLIMÉRICA }\end{array}$ & $\begin{array}{l}\text { SOLO + 4\% DE } \\
\text { ASSOCIAÇÃO } \\
\text { POLIMÉRICA }\end{array}$ & $\begin{array}{l}\text { SOLO + } 6 \% \text { DE } \\
\text { ASSOCIAÇÃO } \\
\text { POLIMÉRICA }\end{array}$ \\
\hline \multicolumn{2}{|c|}{ Massa específica real $\left(\mathrm{g} / \mathrm{cm}^{3}\right)$} & 2,644 & 2,640 & 2,636 & 2,636 \\
\hline \multirow{3}{*}{$\begin{array}{l}\text { Limites de Atter- } \\
\text { berg }\end{array}$} & LL (\%) & 37,5 & 36,4 & 32,7 & 32,0 \\
\hline & LP (\%) & 17,5 & 18,6 & 19,1 & 18,5 \\
\hline & IP (\%) & 20,0 & 17,8 & 13,6 & 13,5 \\
\hline \multicolumn{2}{|c|}{ Classificação TRB - AASHTO } & A -6 & A -6 & A -6 & A -6 \\
\hline \multicolumn{2}{|c|}{ Classificação SUCS } & CL & CL & CL & CL \\
\hline
\end{tabular}

De acordo com o sistema unificado de classificação, os materiais (solo puro e solo adicionado com polímero) se enquadram na classe CL, visto que mais de $50 \%$ do material passa na peneira $\mathrm{n}^{\circ}$. 200, que, quando observados os valores de LL e IP, os materiais são classificados como argila inorgânica de média plasticidade ou argila pedregulhosa, arenosa e siltosa.

Do exposto, considerando as especificações aplicadas ao uso de solos em pavimentação [19], o solo puro e as misturas com polímero não seriam indicadas para uso como material de base de pavimentos, por possuírem LL superior a 25\% e IP acima de 6\%.

Na Figura 4 e na Tabela 3 estão apresentados os resultados obtidos dos ensaios de compactação realizados com o solo puro e as misturas preparadas para este estudo, utilizando energia intermediária do ensaio Proctor. Os resultados obtidos indicaram que a adição do aglutinante ao solo resultou no aumento no teor de umidade ótima das misturas, da ordem de 5,9\%, quando se adicionou 6\% de polímero. Por outro lado, houve redução do peso específico aparente seco máximo da ordem de 6,6\%, quando se adicionou 6\% da associação polimérica. Isso já era esperado, tendo-se em vista que está se adicionando ao solo um material com peso específico inferior, conforme antes mencionado. Este aspecto corrobora com o mencionado por INGLES \& METCALF [21].

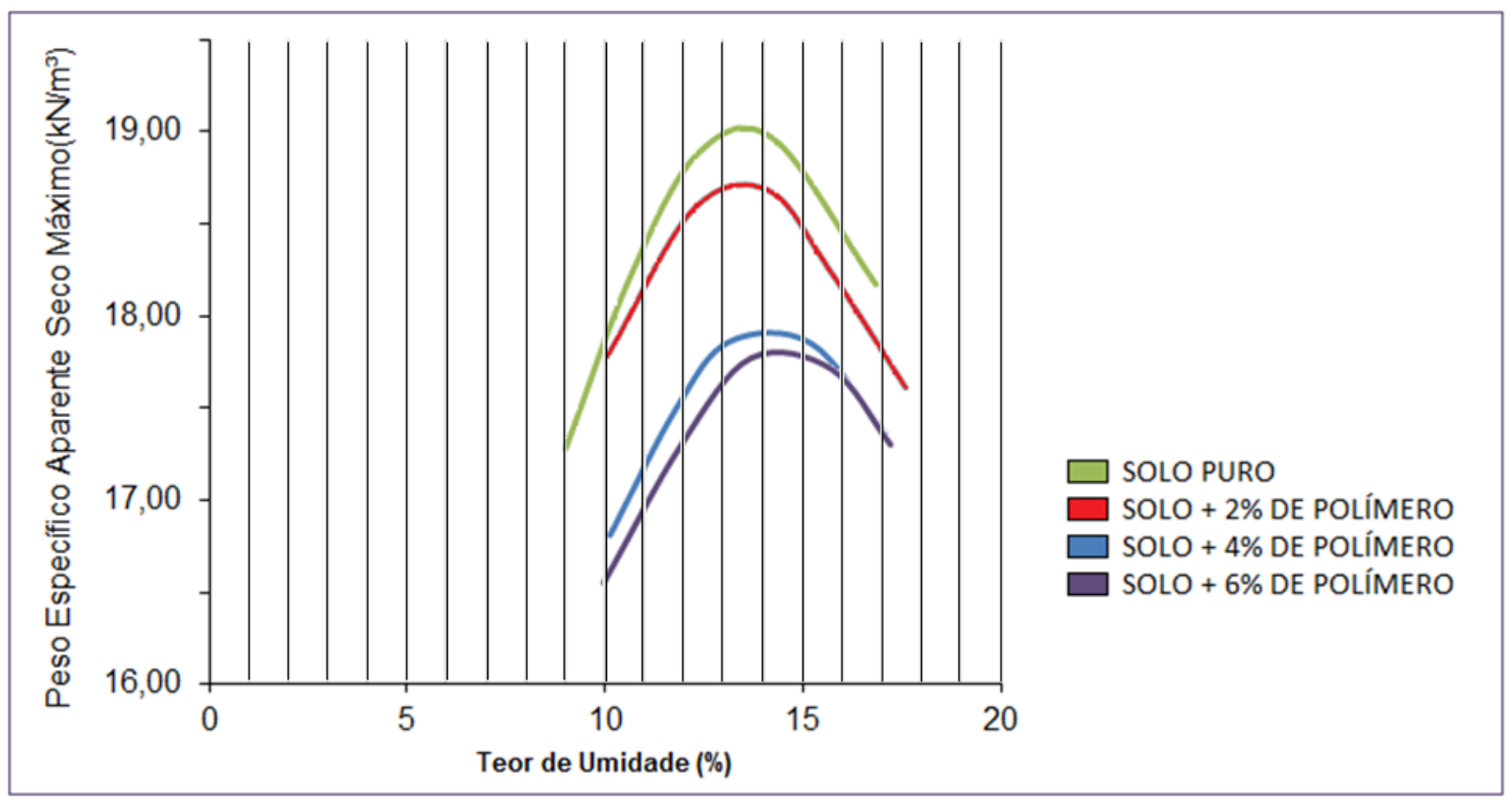

Figura 4: Curva de compactação para as amostras de solo puro e com adição de polímero. 
Tabela 3: Teores de umidade ótima e peso específico aparente seco máximo para as amostras de solo puro de misturas solo-aditivo (associação polimérica).

\begin{tabular}{l|l|l}
\hline COMPOSIÇÃo & $\begin{array}{l}\text { TEOR DE } \\
\text { UMIDADE } \\
\text { ÓTIMA }(\%)\end{array}$ & $\begin{array}{l}\text { MASSA ESPECÍFICA APA- } \\
\text { RENTE SECA MÁXIMA } \\
\left(\mathbf{k N} / \mathbf{m}^{3}\right)\end{array}$ \\
\hline $100 \%$ Solo Puro & 13,6 & 19,03 \\
\hline $100 \%$ Solo Puro + 2\% Aditivo & 13,8 & 18,70 \\
\hline $100 \%$ Solo Puro + 4\% Aditivo & 14,0 & 17,96 \\
\hline $100 \%$ Solo Puro + 6\% Aditivo & 14,4 & 17,85 \\
\hline
\end{tabular}

\subsection{Ensaios de resistência e deformabilidade}

Inicialmente foram realizados os ensaios de ISC com o solo puro e, em seguida, com o solo contendo a adição da associação polimérica nos percentuais estabelecidos para esta pesquisa, sem cura e com cura. Os resultados obtidos estão mostrados no gráfico da Figura 5.

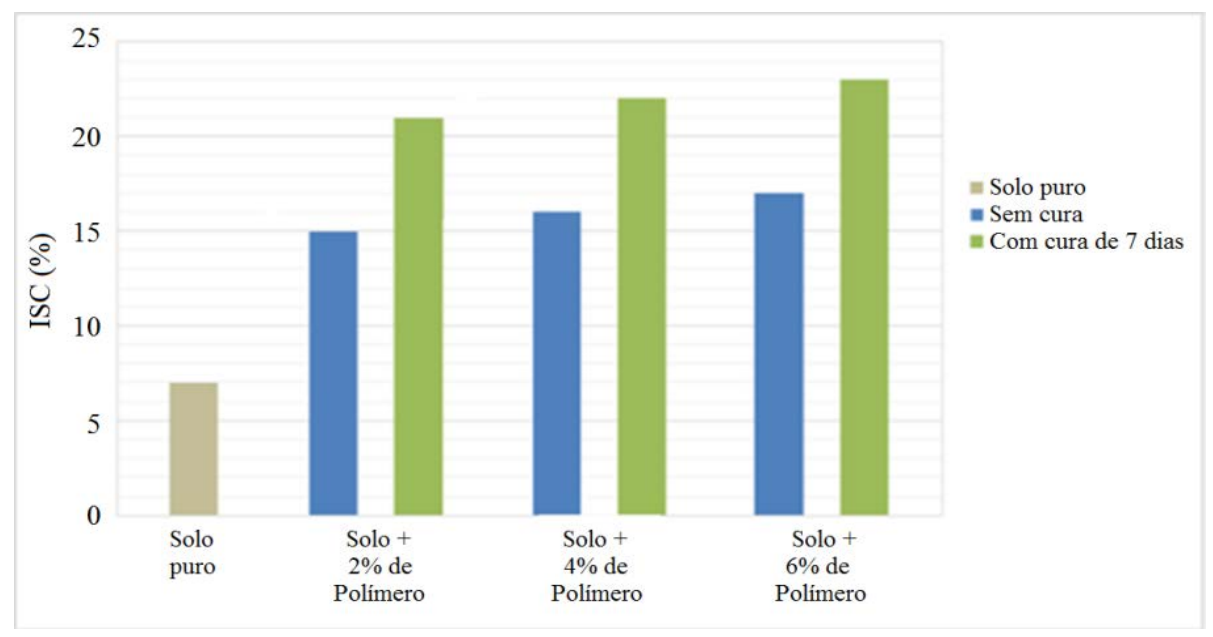

Figura 5: Valores do ISC obtidos para o solo puro e para as misturas com polímero.

Observa-se da figura que o ISC do solo puro é relativamente baixo, da ordem de 7\%, mas experimenta expressivo aumento nos valores, à medida que se faz a adição polimérica, atingindo valores da ordem de $15 \%$ a $22 \%$, mesmo com o percentual mais baixo de polímero, sem e com cura durante um período de 7 dias, respectivamente. Obteve-se um crescimento máximo de 228\%, quando adicionado um teor de 6\%, após uma cura de 7 dias, na comparação ao solo puro. Esse comportamento em termos de aumento de ISC corrobora outra pesquisa com o mesmo produto, desenvolvida por PATRÍCIO [25], o qual mostrou que o aumento nos valores se tornou mais acentuado quando a matriz do solo era composta por areia fina com silte não plástico (A-2-4). A explicação que se pode dar ao fato é que a associação polimérica, quando adicionada ao solo, forma ligações entre as partículas, aumentando a rigidez do material, principalmente após o período de cura.

Com base nas especificações rodoviárias praticadas no Brasil, em termos de ISC, o solo puro não se enquadraria para o uso em camadas de base e sub-base de pavimentos. Para as misturas de solo com associação polimérica, observa-se que, após a cura de 7 dias, obtiveram-se valores de ISC superiores a 20, entretanto inferiores a 40, valor mínimo admitido pelo DNIT ES 98 [20] para uso em camadas de base em rodovia de baixo volume de tráfego, ou seja, vias com $\mathrm{N}<106$ passagens do eixo padrão de 8,2 tf. Ainda assim, o material poderia ser usado em construção de camadas de sub-base, ao contrário do solo puro.

A Figura 6 mostra os valores de expansão obtidos das amostras com as quais foram realizados os ensaios de ISC. Como se pode observar, ocorreu redução na expansão do solo desde o acréscimo de $2 \%$ de polímero, quando a queda é de aproximadamente 60\% para a amostra sem cura, e da ordem 51\% para a amostra com cura de 7 dias. A redução máxima foi obtida com a adição de $6 \%$ da associação polimérica ao solo, quando a expansão experimentou redução da ordem de $66 \%$. 


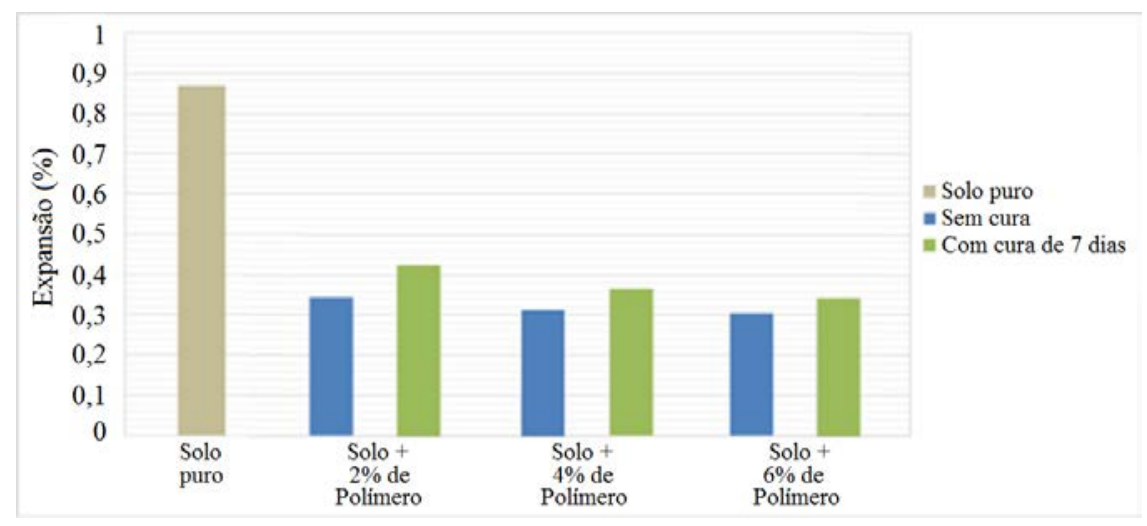

Figura 6: Valores de expansão obtidos para o solo puro e as misturas com polímero.

Esse comportamento relacionado à diminuição da expansão pode ser explicado com base na atuação do redutor de plasticidade, inibindo a troca de íons entre o solo e a água. Como os valores de expansão para materiais de base e sub-base devem ser inferiores a 0,5\% e $1 \%$ respectivamente, todas as misturas de solopolímero dessa pesquisa se enquadrariam nas especificações rodoviárias brasileiras para esse uso, enquanto que o solo puro não poderia ser utilizado como base.

Na Figura 7 são apresentados os resultados obtidos dos ensaios de resistência à compressão simples. Observa-se que há uma nítida tendência de crescimento nos valores de RCS à medida que se aumenta o teor de associação polimérica, alcançando um patamar de crescimento da ordem de 95\% para a mistura solo com 6\% de polímero, após 28 dias de cura, em que o valor de RCS se aproxima de 0,50 MPa, contra 0,26 MPa obtido para o solo puro. Semelhante ao que foi observado com os dados de ISC, a presente tendência também corrobora os resultados obtidos por PATRÍCIO [25], que usou o mesmo polímero em sua pesquisa em outros tipos de solo.

Como a resistência à compressão simples do solo é um parâmetro decorrente da ação coesiva entre as partículas, deduz-se que a associação polimérica adere às partículas do solo, gerando assim uma microestrutura de comportamento coesiva, conforme mencionado por INGLES \& METCALF [21]. Além disso, observa-se que o aumento do tempo de cura contribui para aumentar a RCS, podendo-se atingir ganhos da ordem de $10 \%$, para a amostra com 6\% de polímero e 28 dias de cura, em comparação com o valor obtido aos sete dias de cura.

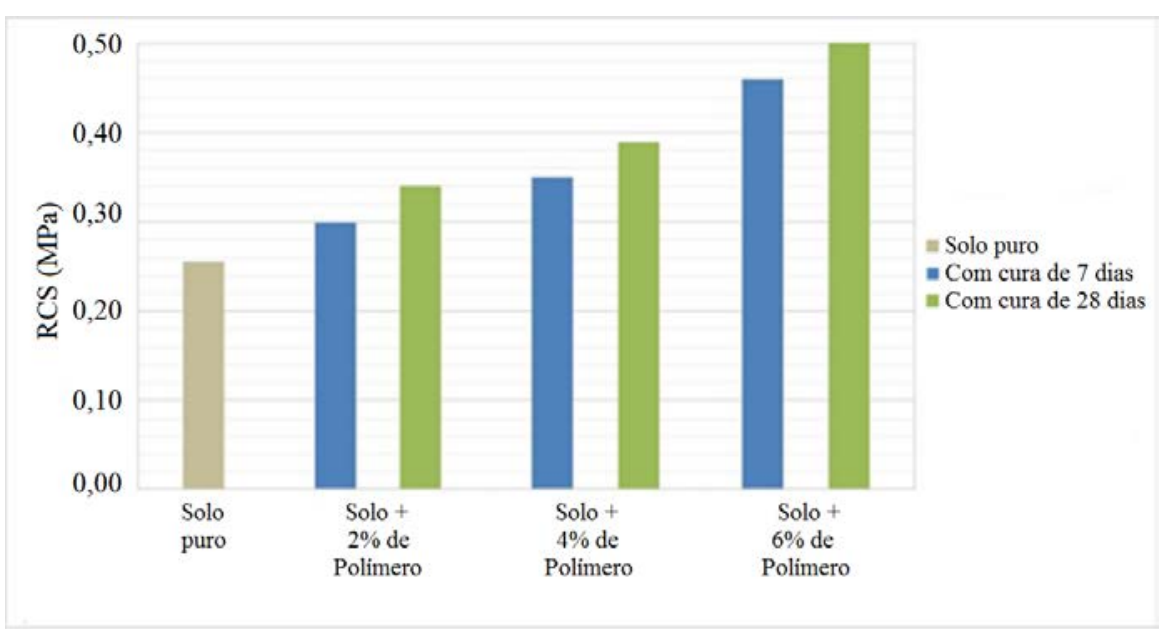

Figura 7: Resistência à compressão simples obtida para o solo puro e para as misturas com associação polimérica.

Os valores de resistência à tração por compressão diametral estão mostrados na Figura 8. Observa-se que os valores de RT aumentaram para todas as amostras, de acordo com o aumento do teor de polímero. Da mesma forma que se observou para os valores de RCS, os valores de RT também foram influenciados pelo tempo de cura, elevando-se em aproximadamente a resistência à tração da mistura com 6\% de polímero, após 28 dias de cura, em relação ao solo puro. Vale ressaltar que as amostras de solo puro e das misturas, mesmo 
apresentando crescimento, apresentaram baixa resistência à tração, ou seja, o crescimento não foi significativo. Para efeitos comparativos, cabe destacar que PATRÍCIO [25] obteve valores máximos de RT da ordem de 0,37 MPa, com 6,4\% de polímero, aos 28 dias de cura.

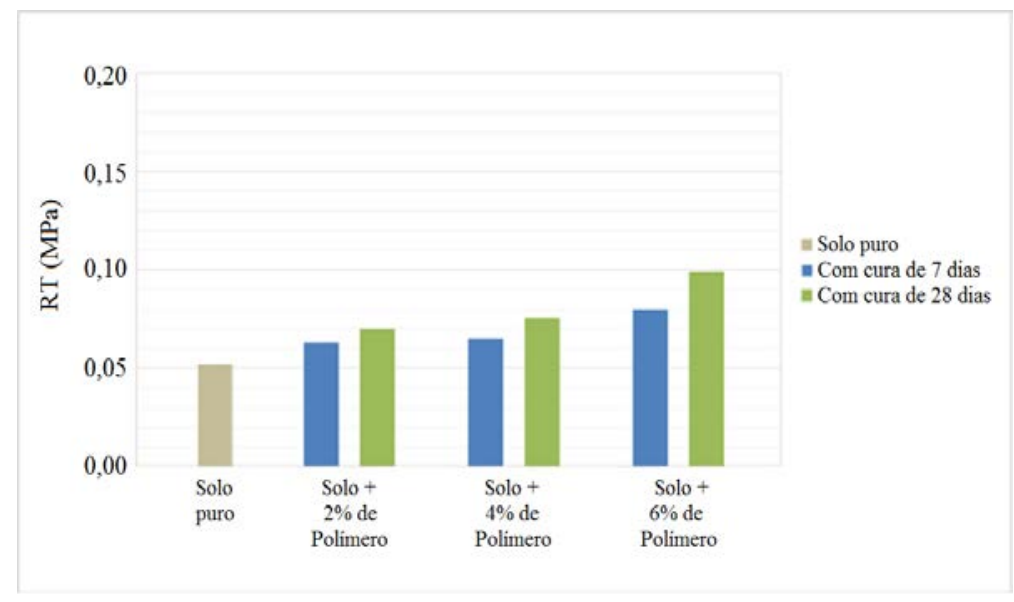

Figura 8: Valores de RT obtidos para o solo puro e mistura solo-associação polimérica.

A Figura 9 mostra os resultados dos ensaios de permeabilidade realizados com o solo puro e com as misturas solo-associação polimérica. Os resultados mostrados revelam que os valores do coeficiente de permeabilidade aumentaram conforme se aumentou o percentual de aditivo nas misturas. O solo puro possuía condutividade hidráulica da ordem de $8,47 \times 10^{-7} \mathrm{~cm} / \mathrm{s}$, considerada muito baixa de acordo com os critérios estabelecidos na hidráulica dos solos, mas, com a adição de $2 \%$ de associação polimérica, o valor aumentou para $3,80 \times 10^{-6}$, crescendo um pouco mais com o teor de $4 \%$, e, finalmente, atingindo o patamar de $4,93 \times 10^{-6}$, com $6 \%$ do produto, superando em mais de cinco vezes o valor obtido para o solo puro. Essa tendência revelada nos resultados se deve, possivelmente, ao fato da redução do índice de plasticidade das misturas, pois à medida que o teor de associação polimérica foi aumentado, o compósito formado pelas partículas e o aglomerante pode ter formado uma estrutura floculada, gerando mais vazios, que, de alguma forma, facilitaram a passagem da água, em comparação ao solo puro. Isto também corrobora com as afirmações de INGLES \& METCALF [21].

Todavia, embora a mistura solo-associação polimérica tenha ficado com condutividade hidráulica maior do que a o solo puro, a floculação dos compostos granulares, formados pela interação entre as partículas do solo e a associação polimérica, possivelmente foi a responsável por essa mudança. Mas, ainda assim, o material pode ser considerado como de baixa permeabilidade, sendo assim classificados os solos que possuem valores de coeficientes de permeabilidade entre $10^{-5}$ a $10^{-7} \mathrm{~cm} / \mathrm{s}$ [10]. O fato de a permeabilidade ter aumentado, mas ainda continuar num patamar de valor baixo tem repercussão favorável para o fim que se deseja à mistura. Ou seja, para camadas de base e/ou sub-base pavimentos, material com baixa permeabilidade representa menor suscetibilidade à ação da água, mantidas as suas propriedades de resistência e deformabilidade. 


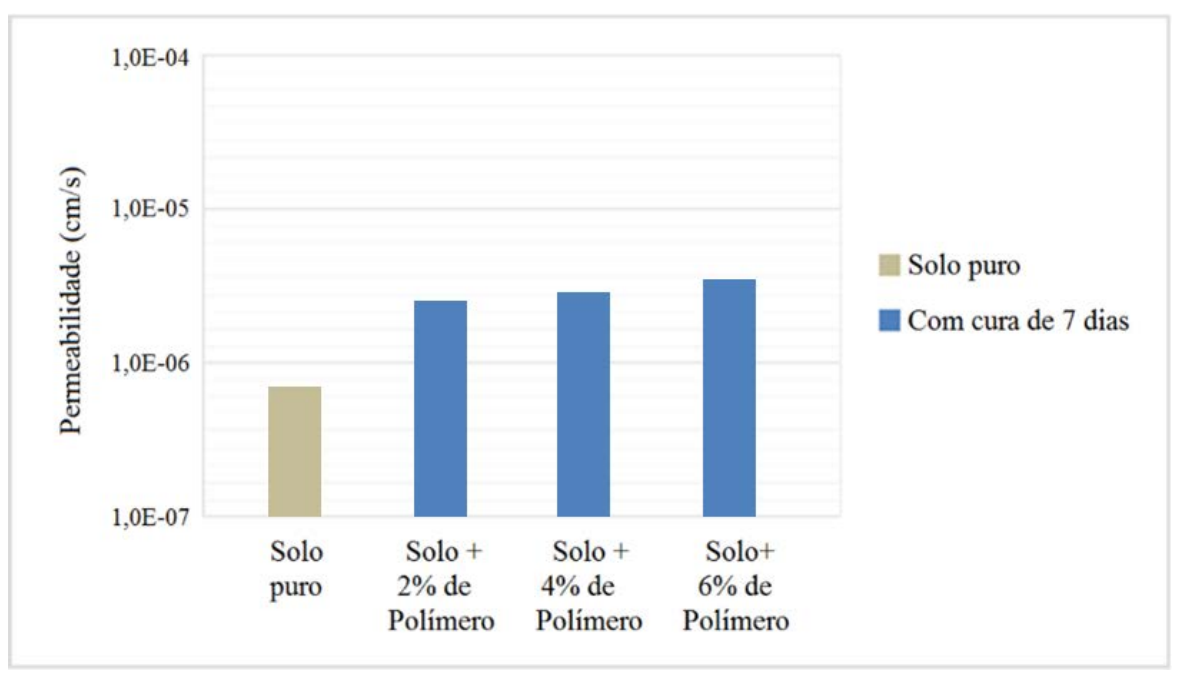

Figura 9: Valores do coeficiente de permeabilidade do solo puro e das misturas solo-polímero.

\section{CONCLUSÕES}

O emprego de polímeros industriais como produtos melhoradores de resistência de solos finos parece se constituir em mais uma interessante alternativa de aproveitamento de solos descartados da cadeia produtiva da pavimentação, reduzindo os impactos ambientais causados pela exploração em busca de jazidas de qualidade adequada.

Nesta pesquisa, foi utilizado, em associação com o polímero, um produto redutor de plasticidade, que demonstrou a capacidade para diminuir o índice de plasticidade do solo argilo-siltoso, usado em até $48 \%$, mas não o suficiente para permitir que este pudesse ser utilizado como material de base de pavimentos.

De acordo com as especificações tradicionais brasileiras, o solo da jazida usada neste trabalho não poderia ser utilizado no estado puro, nem em camada de base, nem de sub-base, por seus valores de plasticidade e expansão e baixo valor de ISC. Entretanto, quando ao solo foi adicionado um teor de 6\% de associação polimérica, os valores de ISC cresceram e os de expansão diminuíram a patamares que permitem o material ser utilizado na construção de camadas de sub-base de pavimentos.

O produto polimérico promoveu melhorias significativas no comportamento mecânico do solo, à medida que a resistência à compressão simples aumentou em até 95\%, para a mistura solo com 6\% de associação polimérica, e em até $90 \%$, para a resistência à tração por compressão diametral do solo estudado.

A adição da associação polimérica ao solo promoveu a elevação do coeficiente de permeabilidade do solo em mais de cinco vezes, com o percentual de $6 \%$ do aditivo, possivelmente devido à floculação dos compostos granulares formados pela interação entre as partículas do solo e a associação polimérica.

\section{AGRADECIMENTOS}

A todos que contribuíram com a pesquisa, em especial à Universidade Federal de Sergipe pela estrutura de laboratórios disponibilizada, à empresa ViaEncosta Engenharia Ambiental, por doar parte do material utilizado neste estudo, e à CAPES pelo apoio financeiro concedido (bolsa) durante todo o período da pesquisa.

\section{BIBLIOGRAFIA}

[1] ASSOCIAÇÃO BRASILEIRA DE NORMAS TÉCNICAS. NBR 7182: Solos - Ensaio de Compactação. Método de Ensaio, 1986.

[2] ASSOCIAÇÃO BRASILEIRA DE NORMAS TÉCNICAS. NBR 9895: Solos - Índice Suporte Califórnia. Método de Ensaio, 1987.

[3] ASSOCIAÇÃO BRASILEIRA DE NORMAS TÉCNICAS. NBR 12770: Solo coesivo - Determinação de compressão não confinada, Rio de Janeiro, 1992.

[4] ASSOCIAÇÃO BRASILEIRA DE NORMAS TÉCNICAS. NBR 14545: Solo - Determinação do coeficiente de permeabilidade de solos argilosos a carga variável, Rio de Janeiro, 2000. 
[5] ASSOCIAÇÃO BRASILEIRA DE NORMAS TÉCNICAS. NBR 10004: Resíduos sólidos - Classificação, Rio de Janeiro, 2004.

[6] BALBO, J.T., Pavimentação asfáltica: materiais, projetos e restauração, São Paulo, Oficina de Textos, 2007.

[7] BASTOS, C.A.B., INSTITUTO FEDERAL DO ESPÍRITO SANTO, ftp://ftp.ifes.edu.br/cursos/Transportes/CelioDavilla/Solos/Literatura\%20complementar/Apostila\%20FURG \%20Solos/09\%20-\%20ESTABILIZACAO.pdf. Acessado em janeiro de 2016.

[8] CAVALCANTE, E.H. et al., "Avaliação de propriedades mecânicas de misturas solo-emulsão”, In: COBRAMSEG 2010: Engenharia Geotécnica para o desenvolvimento, inovação e sustentabilidade, Gramado, Brasil, 2010.

[9] CORDEIRO, J.K. da S., Estabilização química e solidificação do resíduo oleoso gerado nas atividades de E\&P de petróleo, com solo para o uso em camadas de bases elou sub-bases de pavimentos rodoviário, Dissertação de Msc., UFCG, Campina Grande, Paraíba, Brasil, 2007.

[10] DAS, B. M., Advanced Soil Mechanics, 2 ed., Washington, Taylor \& Francis, 1997.

[11] D. AFRICON, http://www.dirtglueafricon.com/\#!dust-control-potholeroad-building/c1oqu. Acessado em fevereiro de 2016.

[12] DEPARTAMENTO NACIONAL DE INFRAESTRUTURA DE TRANSPORTES. ME-051/1994: Solos - Análise granulométrica, Rio de Janeiro, 1994.

[13] DEPARTAMENTO NACIONAL DE INFRAESTRUTURA DE TRANSPORTES. ME-082/1994: Solos - Determinação do limite de plasticidade, Rio de Janeiro, 1994.

[14] DEPARTAMENTO NACIONAL DE INFRAESTRUTURA DE TRANSPORTES. ME-093/1994: Solos - Determinação da densidade real, Rio de Janeiro, 1994.

[15] DEPARTAMENTO NACIONAL DE INFRAESTRUTURA DE TRANSPORTES. ME-122/1994: Solos - Determinação do limite de liquidez, Rio de Janeiro, 1994.

[16] DEPARTAMENTO NACIONAL DE INFRAESTRUTURA DE TRANSPORTES. ME-181/1994: Solos estabilizados com cinza volante e cal hidratada - determinação da resistência à tração por compressão diametral, Rio de Janeiro, 1994.

[17] DEPARTAMENTO NACIONAL DE INFRAESTRUTURA DE TRANSPORTES. ES-301/1997: Pavimentação - Sub-base estabilizada granulometricamente, Rio de Janeiro, 1997.

[18] DEPARTAMENTO NACIONAL DE INFRAESTRUTURA DE TRANSPORTES. ES-303/1997: Pavimentação - Base estabilizada granulometricamente, Rio de Janeiro, 1997.

[19] DEPARTAMENTO NACIONAL DE INFRA-ESTRUTURA DE TRANSPORTES. Manual de pavimentação, Rio de Janeiro: IPR, 3 ed., 2006.

[20] DEPARTAMENTO NACIONAL DE INFRAESTRUTURA DE TRANSPORTES. ES-98/2007: Pavimentação - base estabilizada granulometricamente com utilização de solo laterítico - especificação de serviço, Rio de Janeiro, 2007.

[21] INGLES, O.G., AND METCALF, J.B. Soil Stabilization - Principles and Practice. Butterworths Pty. Limited. Melbourne, Australia, 1972.

[22] MARTINS, W. Casos de obra de estradas construídas com misturas de solo-polímero: ViaEncosta, Recife, Pernambuco, Brasil, 2013.

[23] MORAIS, C. J., Avaliação do uso de polímero adicionado a solos e resíduos da produção de petróleo como materiais alternativos para pavimentos, UFS, São Cristóvão, Sergipe, Brasil, 2015.

[24] OLIVEIRA, L.C.D. de. A estabilização de solos aplicada a habitação, um estudo de misturas solocimento, Dissertação de MSc., UFRJ, Rio de Janeiro, Brasil, 1994.

[25] PATRÍCIO, J.D., Estudo de solos modificados por adição de polímeros para uso em pavimento rodoviários, Dissertação de MSc., UFCG, Campina Grande, Paraíba, Brasil, 2015.

[26] RAMOS, I. S., LEAL, C.L.D., FERNANDES NETO, L., et al., PORTAL ESTÁCIO, http://portal.estacio.br/media/4588538/solo\%20later\%C3\%ADtico\%20estabilizado\%20com\%20cal.pdf. Acesso em janeiro de 2016.

[27] SANTOS, C.B. Estabilização / solidificação de resíduo da indústria de petróleo para uso em pavimentos rodoviários, Dissertação de MSc., UFCG, Campina Grande, Paraíba, Brasil, 2010. 
[28] SOUSA, I. M. Utilização de resíduo oleoso proveniente da indústria de petróleo aplicando a técnica de estabilização/solidificação em camadas de base de pavimentos, UFERSA, Mossoró, Rio Grande do Norte, Brasil, 2014.

[29] SOLIZ, V.V.P., Estudo de três solos estabilizados com emulsão asfáltica, Dissertação de MSc., UFRJ, Rio de Janeiro, Brasil, 2007.

[30] TINGLE, J. S., et al., "Stabilization Mechanisms of Nontraditional Additives. Journal of the Transportation Research Board”. Washington: Transportation Research Board of the National Academies, v. 2, n. 1989, 2007. 